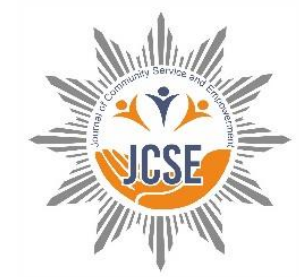

\title{
Building and protecting business through intellectual property rights
}

\author{
Edy Purwanto ${ }^{a, 1, *}$, Mohammad Hidayaturrahman ${ }^{b, 2}$ \\ ${ }^{a}$ Department of Management, Faculty of Economics and Business, Universitas Wiraraja, Jl. Raya Sumenep-Pamekasan KM. 05 Patean, Panitian Utara, \\ Patean, Batuan, Kabupaten Sumenep, East Java 69451 Indonesia \\ ${ }^{b}$ Department of Public Administration, Faculty of Social and Political Sciences, Universitas Wiraraja, Jl. Raya Sumenep-Pamekasan KM. 05 Patean, \\ Panitian Utara, Patean, Batuan, Kabupaten Sumenep, East Java 69451 Indonesia \\ ${ }^{1}$ edypurwanto@wiraraja.ac.id*; ${ }^{2}$ hidayaturrahman@wiraraja.ac.id \\ * Corresponding author
}

\begin{tabular}{|c|c|}
\hline ARTICLE INFO & ABSTRACT \\
\hline $\begin{array}{l}\text { Article history } \\
\text { Received: 2020-09-04 } \\
\text { Revised: 2021-03-12 } \\
\text { Accepted: 2021-03-16 } \\
\text { Published: 2021-04-19 } \\
\text { Keywords } \\
\text { Intellectual property rights } \\
\text { MSME } \\
\text { Pagerungan Besar }\end{array}$ & $\begin{array}{l}\text { Pagerungan Besar is one of the villages in Sapeken District which has quite a good marine and } \\
\text { agricultural product potential. MSME actors in Pagerungan Besar are currently starting to } \\
\text { develop, but there are concerns about the large number of counterfeit products that can damage } \\
\text { the brand or product image that has been grown up. This activity was aimed to provide } \\
\text { understanding to MSME actors in Pagerungan Besar Village regarding Intellectual Property } \\
\text { Rights. Activities carried out in the form of socialization and assistance. This method is the right } \\
\text { way to solve the problems experienced by MSME actors in Pagerungan Besar. There was } 30 \\
\text { MSME actor who attended the socialization and mentoring activities. The results of this activity } \\
\text { indicate that there is a significant change in the respondent's understanding of intellectual } \\
\text { property rights. Before the socialization, only } 5 \text { participants (15\%) knew and had heard of IPR, but } \\
\text { after the socialization, } 30 \text { participants (100\%) already understood IPR. Furthermore, assistance } \\
\text { efforts must be carried out until the MSME actors have the rights to the works they own, be it } \\
\text { trademarks, copyrights and, other intellectual property rights. }\end{array}$ \\
\hline
\end{tabular}

\section{Kata kunci}

Hak kekayaan intelektual

MSME

Pagerungan Besar

\begin{abstract}
Membangun dan melindungi bisnis melalui hak kekayaan intelektual. Pagerungan Besar merupakan salah satu desa di Kecamatan Sapeken yang memiliki potensi hasil pertanian dan kelautan yang cukup baik. Pelaku UMKM di Pagerungan Besar saat ini sudah mulai berkembang, namun terdapat kekhawatiran banyaknya produk palsu yang dapat merusak brand atau image produk yang sudah dewasa. Kegiatan ini bertujuan untuk memberikan pemahaman kepada pelaku UMKM di Desa Pagerungan Besar tentang Hak Kekayaan Intelektual. Kegiatan yang dilakukan berupa sosialisasi dan pendampingan. Cara ini merupakan cara yang tepat untuk menyelesaikan permasalahan yang dialami oleh pelaku UMKM di Pagerungan Besar. Ada 30 pelaku UMKM yang mengikuti kegiatan sosialisasi dan pendampingan. Hasil dari kegiatan ini menunjukkan bahwa terdapat perubahan yang signifikan pada pemahaman responden tentang hak atas kekayaan intelektual. Sebelum sosialisasi hanya 5 peserta (15\%) yang mengetahui dan pernah mendengar tentang HKI, namun setelah sosialisasi, 30 peserta (100\%) sudah memahami HKI. Selanjutnya, upaya pendampingan harus dilakukan hingga pelaku UMKM memiliki hak atas ciptaan yang dimilikinya, baik merek dagang, hak cipta, maupun hak kekayaan intelektual lainnya.
\end{abstract}

Copyright (C) 2021, Purwanto \& Hidayaturrahman

\section{Check for updates}

This is an open access article under the CC-BY-SA license

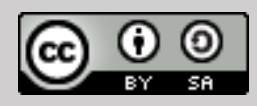

How to cite: Purwanto, E., \& Hidayaturrahman, M. (2021). Building and protecting business through intellectual property rights. Journal of Community Service and Empowerment, 2(1), 8-12. https://doi.org/10.22219/jcse.v2i1.13513

\section{PENDAHULUAN}

Sumenep merupakan kabupaten yang ada di provinsi Jawa Timur dengan wilayah yang terdiri dari daratan dan kepulauan. Salah satu kecamatan yang ada di kepulauan adalah Sapeken. Kecamatan ini memiliki 11 desa yang tersebar di beberapa pulau kecil. Desa Pagerungan Besar merupakan salah satu desa yang ada di Kecamatan Sapeken. Menurut 
Badan Pusat Statistik, (2019), Pagerungan Besar memiliki luas wilayah $3.12 \mathrm{KM}^{2}$ dengan jumlahl penduduk 6.533 Jiwa (laki-laki, 3.293 jiwa dan perempuan, 3.240 jiwa). Pagerungan Besar terletak di ujung timur Kabupaten Sumenep, Pelaku UMKM di Desa Pagerungan Besar jarang tersentuh oleh para akademisi terutama untuk mengembangkan usaha yang mereka miliki. Jarak dari Kabupaten Sumenep ke Pagerungan Besar sekitar $222 \mathrm{KM}$ sehingga sangat wajar jika pelaku usaha jarang mendapatkan edukasi dan pendampingan usaha. Untuk itu, mereka membutuhkan sentuhan dari para akademisi untuk memberikan pemahaman di berbagai sektor terutama mengenai Hak Kekayaan Intelektual.

Beberapa tahun terakhir Pemerintah Kabupaten Sumenep mendorong masyarakat agar termotivasi untuk mendirikan usaha. Program yang dilaksanakan oleh Pemerintah Kabupaten Sumenep ini merupakan manifestasi dari program pemerintah untuk meningkatkan jumlah UMKM di Indonesia. Banyak negara termasuk Indonesia menjadikan usaha mikro, kecil, dan menengah (UMKM) sebagai Tulang punggung perekonomian. Selain dijadikan garda terdepan dalam perekonomian, UMKM juga merupakan wadah strategis untuk menyediakan tenaga kerja mandiri. Indonesia saat ini terus berupaya untuk meningkatkan perekonomian demi meningkatkan taraf kemakmuran dan kesejahteraan rakyatnya (Herliansyah et al., 2019).

Pagerungan Besar merupakan salah satu desa dengan hasil laut dan hasil bumi yang cukup baik. Potensi tersebut merupakan kesempatan besar bagi para pelaku usaha untuk memanfaatkan setiap potensi untuk dikelola menjadi produk yang siap bersaing di pasar. Jumlah pelaku UMKM di Pagerungan Besar yaitu 23 Home Industry dan 2 untuk katogeri Small Industri (BPS, 2019). UMKM merupakan usaha produktif yang bisa diklasifikasikan berdasarkan kekayaan bersih dan hasil penjualan tahunan (Ismail, 2011). Salah satu industri yang cukup terkenal di Pagerungan Besar adalah industri kerajinan dari kayu santegi. Industri ini sudah berjalan puluhan tahun. Setiap karya yang mereka hasilkan memiliki bentuk dan karakter yang unik. Berdasarkan interview kepada salah satu pengrajin, mereka menyampaikan bahwa mereka tidak pernah mendaftarkan karya mereka karena tidak mengetahui hak kekayaan intelektual.

Interview yang dilakukan kepada ibu Thahira (pelaku UMKM) didapatkan informasi bahwa pelaku usaha di Pagerungan Besar sangat membutuhkan edukasi dan pendampingan mengenai hak kekayaan intelektual. Bisnis yang mereka dirikan sudah cukup produktif sehingga perlindungan terhadap merek dagang yang merek miliki perlu didaftarkan untuk mendapatkan legalitas. Ketidaktahuan mengenai HKI menjadi penghalang dalam memajukan usaha. Pernyataan tersebut didukung oleh Brem et al (2017) yang menyampaikan bahwa hak kekayaan intelektual memiliki dampak yang signifikan pada pangsa pasar dan kinerja sebuah perusahaan. Hak kekayaan intelektual merupakan elemen penting karena HKI dapat memberikan keunggulan kompetitif. Selai itu, HKI juga dapat mendorong berbagai inovasi (Yanto et al., 2019). Menurut Aswin et al (2019) hak kekayaan intelektual merupakan hak eksklusif bagi pemilik karya. Secara hukum hak kekayaan intelektual dapat dikategorikan menjadi Hak Cipta dan Hak Kekayaan Industri.

Era globalisasi ditandai dengan tingginya tingkat persaingan antar produk (Surugiu \& Surugiu, 2015; Tang et al., 2020). Dengan demikian, hak kekayaan intelektual memiliki peranan yang penting untuk melindungi setiap karya yang dihasilkan oleh pelaku usaha (Atun et al., 2020). UMKM dalam satu daerah berpotensi menghasilkan produk yang sama sehingga hak kekayaan intelektual sangat diperlukan untuk melindungi setiap karya-karya yang sudah dihasilkan. Tujuan dari Kegiatan sosialisasi dan pendampingan ini yaitu untuk memberikan pemahaman kepada pelaku UMKM Desa Pagerungan Besar tentang pentingnya Hak Kekayaan Intelektual. Selain itu, untuk memberikan pemahaman tentang prosedur pendaftaran dan pemberkasan dalam pengurusan Hak Kekayaan Intelektual.

\section{METODE}

Pelaksanaan kegiatan pengabdian kepada masyarakat dalam upaya menumbuhkan dan melindungi usaha pelaku UMKM di desa Pagerungan Besar melalui Hak Kekayaan intelektual (HKI) adalah sebagai berikut:

\section{Sosialisasi}

Kegiatan sosialiasasi dilakukan untuk memberikan pemahaman kepada pelaku UMKM tentang pentingnya Hak Kekayaan Intelektual dan dampaknya terhadap keberlanjutan usaha. Kegiatan sosialisasi ini diikuti oleh 30 pelaku UMKM di Desa Pagerungan Besar. Pemerintah desa sebagai mitra dalam pengabdian masyarakat ini juga mendorong pelaku UMKM untuk memastikan usaha mereka selalu aman dari tindakan-tindakan yang dapat merugikan usaha mereka. Penyampaian materi tentang hak kekayaan intelktual disampaikan oleh Edy Purwanto, SE., M.Sc selaku ketua pelaksana kegiatan sekaligus kepala sentra HKI Univesitas Wiraraja.

\section{Pelatihan dan pendampingan}

Pelatihan tentang penulisan formulir hak cipta dan formulir merek dilakukan setelah kegiatan sosialisasi. Kegiatan ini dilakukan dengan memberikan formulir pendaftaran hak cipta dan formulir pendaftaran merek kepada peserta kegiatan. Selanjutnya pemateri memberikan petunjuk mengenai hal-hal apa saja yang perlu dilengkapi untuk melakukan pendaftaran hak cipta dan pendaftaran merek.

Kegiatan sosialisasi dan pelatihan dilaksanakan di gelanggang olahraga (GOR) desa pagerungan Besar. Pemilihan gelanggang karena tempatnya terbuka sehingga memberikan kesempatan bagi masyarakat pagerungan besar untuk menyimak materi yang disampaikan. Jumlah pelaku UMKM yang hadir dalam kegaitan ini yaitu sebanyak 30 partisipan 
(pelaku UMKM. Penggunaan 30 partisipan dalam kegiatan ini didasarkan data pelaku UMKM yang diberikan pemerintah desa. Teknik ini merupakan purposive sampling yaitu teknik penentuan sampel berdasarkan pertimbangan atau tujuan tertentu (Sugiyono, 2018).

Sebelum kegiatan sosialisasi dan pendampingan dimulai peserta diberikan pre-test dan setelah kegiatan peserta kegiatan diberikan post-test. Pertanyaan tersebut berisi tentang apakah peserta mengetahui dan pernah mendengar HKI dan apakah peserta mengetahui prosedur pendaftaran HKI. Pertanyaan tersebut akan dijadikan indikator keberhasilan atas kegiatan sosialisasi dan pendampingan yang dilakukan. Data yang didapatkan akan dianalisis menggunakan analisis deskriptif.

\section{HASIL DAN PEMBAHASAN}

\section{Tahap Persiapan Pelaksanaan}

Pada tahap persiapan, tim pengabdian kepada masyarakat mempersiapkan materi berupa power point (PPT) tentang hak kekayaan intelektual, menyiapkan formulir dalam kegiatan pelatihan dan pendampingan pengisian formulir hak cipta dan formulir pendaftaran merek, mengurus perizinan dan meminta data pelaku usaha mikro kecil menengah (UMKM) kepada pemerintah desa pagerungan Besar. Selanjutnya, tim berkoordinasi dengan pemerintah desa mengenai tempat dan waktu pelaksanaan kegiatan sosialisasi dan pendampingan.

\section{Tahap Pelaksanaan}

Kegiatan Sosialisasi dan pendampingan Hak kekayaan Intelektual bagi pelaku UMKM dilaksanakan di Gelanggang Remaja Pagerungan Besar pada hari Jum'at tanggal 21 Agustus 2020. Kegiatan sosialisasi dan pendampingan diikuti oleh pelaku usaha, dan pemerintah desa Pagerungan Besar. Terdapat 30 peserta yang mengikuti kegiatan sosialisasi dan pendampingan HKI. Peserta kegiatan sosialisasi dan pendampingan dapat dilihat pada Tabel 1.

Tabel 1. Latar belakang peserta sosialisasi

\begin{tabular}{cll}
\hline No & \multicolumn{1}{c}{ Latar Belakang } & \multicolumn{1}{c}{ Keterangan } \\
\hline 1 & Pemerintah Desa & PEMDES, BPD, BUMDES \\
2 & Pengusaha & Abon Ikan, Keripik Singkong, Pengrajin Kayu Santegi, Jamu, Kreasi Bunga, \\
& & Rumput Laut, Sumur Bor, Tahu, Kue Bolu, Toko Pakaian \\
\hline
\end{tabular}

Kegiatan dimulai dengan pemberian kuisioner pre-test kepada peserta. Tujuannya untuk memperoleh informasi tentang pemahaman peserta tentang hak kekayaan inteleketual. Hasilnya menunjukkan bahwa peserta yang mengetahui atau pernah mendengar tentang hak kekayaan intelektual sebanyak 5 orang (15\%) dan 25 orang (85\%) yang menjawab tidak tau. Kemudian, pertanyaan tentang pengetahuan peserta tentang prosedur pendaftaran HKI, sebanyak 30 orang (100\%) menjawab tidak tahu.

Rincian kegiatan pada tahap pelaksanaan dapat dilihat dalam Tabel 2.

Tabel 2. Kegiatan pada tahap pelaksanaan

\begin{tabular}{cll}
\hline No & \multicolumn{1}{c}{ Kegiatan utama } & \multicolumn{1}{c}{ Rincian kegiatan } \\
\hline 1 & Sosialisasi & 1. Memberikan kuisioner pre-test \\
& & 2. Menyampaikan materi tentang hak kekayaan intelektual (apa itu HKI, pentingnya \\
& & HKI, Jenis HKI)
\end{tabular}

Pelaksanaan kegiatan sosialisasi dimulai dengan penyampaian materi tentang hak kekayaan intelektual. Penyampaian materi menggunakan alat bantu berupa Proyektor karena materi yang disampaikan menggunakan power point (Gambar 1). Hal ini dimaksudkan agar para peserta tertarik dan menyimak materi yang disampaikan dan lebih mudah memberikan pemahaman kepada peserta karena terdapat beberapa contoh produk yang perlu ditunjukkan kepada peserta. Substansi dari materi yang diberikan yaitu pengertian HKI, pentingnya HKI dalam membangun dan melindungi usaha yang mereka miliki, jenis HKI dan prosedur dan persyaratan pendaftaran hak cipta dan pendaftaran merek.

Pada saat kegiatan berlangsung, para peserta (pelaku UMKM) menyampaikan bahwa merek menginginkan untuk mendaftarkan merek dagang dari usaha yang mereka miliki. Pak Dayat yang merupakan satu pelaku usaha di industri Kayu sentigi menyampaikan bahwa produknya sudah memiliki pasar yang jelas bahkan sudah sering mengikuti kegiatan pameran di jawa timur. Dengan demikian, kegiatan sosialisasi ini sangat membantu mereka terutama untuk pemahaman tentang apa yang harus dilakukan untuk memiliki merek dagang sendiri. Peserta kegiatan lainnya juga 
ikut menyampaikan kekhawatiran mereka terhadap keberlangsungan usaha yang mereka miliki dan keinginannya untuk memiliki merek dagang sendiri.

Kegiatan selanjutnya adalah pelatihan tentang penulisan formulir pendaftaran (pemberkasan) pengajuan karya hak kekayaan intelektual yaitu hak cipta dan merek. Para peserta diberikan formulir pendaftaran dan persyaratan lainnya. Selanjutnya para peserta diberikan penjelasan tentang tata cara dan apa saja yang perlu diisi ketika akan mendaftarkan karya mereka. Pada umumnya, hasil pelatihan menunjukkan bahwa para peserta kegiatan sudah memahami tentang apa yang perlu dipersiapkan ketika akan mendaftarkan karya mereka di HKI.

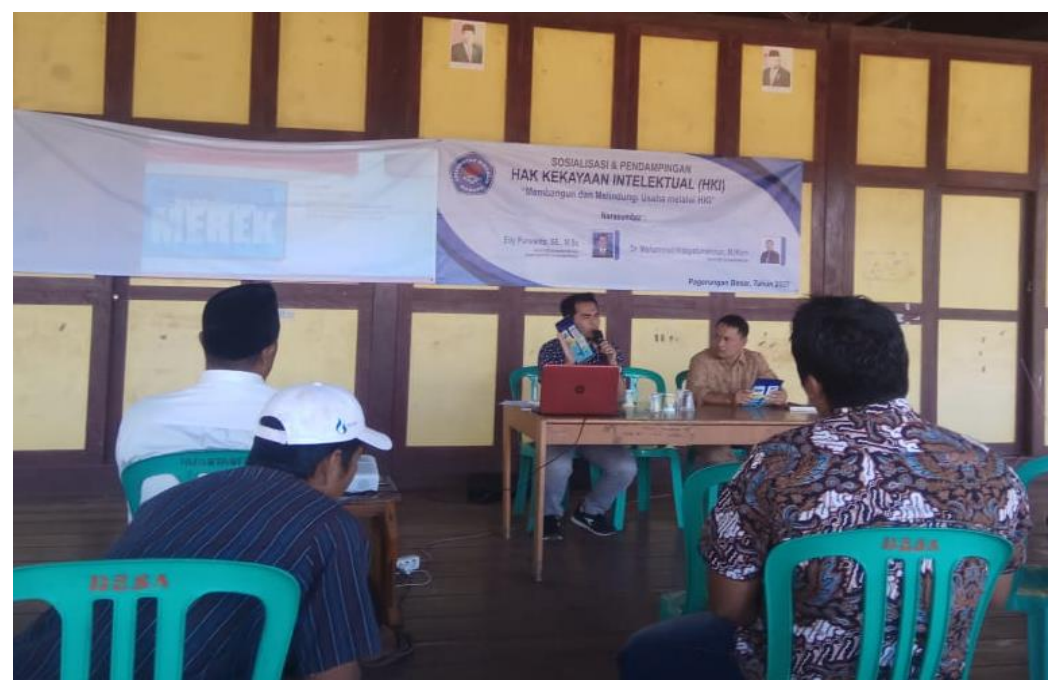

Gambar 1. Penyampaian materi sosialisasi

\section{Tahap evaluasi kegiatan}

Pada tahap evaluasi hasil kegiatan para peserta diberikan kuisioner post test untuk mengetahui dampak kegiatan bagi peserta. Hasilnya menunjukkan bahwa terdapat perubahan yang signifikan dimana pada saat pre test hanyai 5 orang yang mengetahui HKI tetapi setelah kegiatan 30 peserta (100\%) sudah mengetahui hak kekayaan intelektual. Begitupun juga dengan pemahaman tentang pengisian formulir dan pemberkasan pengajuan karya di HKI, semua peserta menjawab sudah memahami. Dengan demikian, kegiatan penyampaian materi dan pelatihan penulisan formulir dan pemberkasan lainnya sudah dipahami dengan baik oleh para peserta.

Pada tahap evaluasi ini juga dilakukan penyusunan rencana tindak lanjut dari kegiatan ini. Tim pengabdian kepada masyarakat berkomitmen untuk tetap memantau dan mendampingi para pelaku UMKM Desa Pagerungan Besar yang akan mendaftarkan karya, produk dan juga merek yang mereka miliki.

Kegiatan sosialisasi dan pendampingan guna membangun dan melindungi usaha melalui hak kekayaan intelektual ditutup dengan sesi foto bersama perwakilan pemerintah desa pagerungan besar, pewakilan pelaku usaha, dan tim pengabdian kepada masyarakat di pulau pagerungan besar.

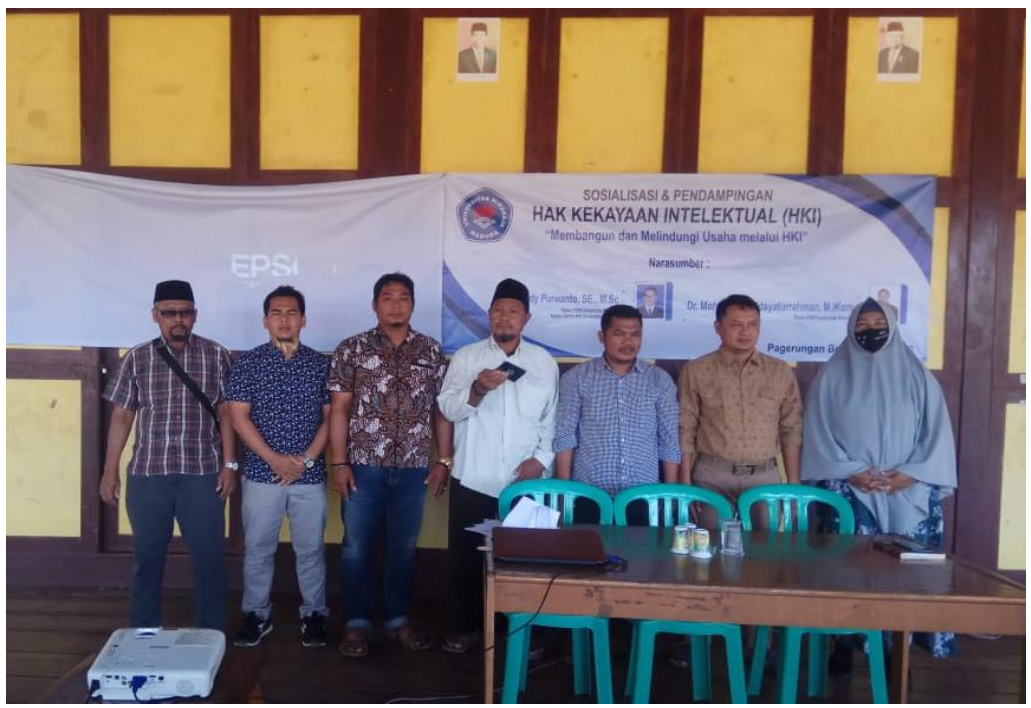

Gambar 2. Foto bersama perwakilan PEMDES, UMKM dan Tim 


\section{KESIMPULAN}

Kesimpulan dari kegiatan sosialisasi dan pendampingan hak kekayaan intelektual yaitu: Dalam pelaksanaan kegiatan para pelaku UMKM sudah memahami tentang pentingnya hak kekayaan intelektual dalam membangun dan melindungi usaha yang mereka miliki. terbukti para peserta kegiatan sebelum kegiatan sosialisasi hanya 5 orang (15\%) yang mengetahui HKI dan $100 \%$ menjawab tidak mengetahui prosedur pendaftaran HKI. Setelah kegiatan sosialisasi, semua peserta kegiatan (100\%) menjawab mengetahui HKI dan prosedur pendaftaran HKI. Selanjutnya, upaya pendampingan dan monitoring masih tetap dilakukan sampai usaha dan produk para pelaku UMKM sudah terdaftar di hak kekayaan intelektual.

\section{UCAPAN TERIMA KASIH}

Terima kasih disampaikan kepada Universitas Wiraraja sebagai sumber pendanaan internal Program pengabdian Masyarakat Tahun Pendanaan 2020 sesuai surat kontrak 045/SP2H/PKM-DI/LPPM/UNIJA/VI/2020.

\section{REFERENSI}

Asri, D. P. B (2020). Perlindungan hukum hak kekayaan intelektual bagi produk kreatif usaha kecil menengah di Yogyakarta. Jurnal Hukum IUS QUIA IUSTUM, 27(1), 130 -150. https://doi.org/10.20885/iustum.vol27.iss1.art7

Aswin, M., \& Arsyad, A. W. (2019). Opini pelaku usaha mikro, kecil dan menengah (UMKM) terhadap sosialisasi hak kekayaan intelektual di Kota Samarinda. eJournal Ilmu Komunikasi, 7(3), 184-195. https://ejournal.ilkom.fisipunmul.ac.id/site/?p=3900

Atun, S., Kasiyan, K., \& Mulyani, E (2020). Sosialisasi hak kekayaan intelektual (HKI) bagi usaha kecil menengah (UKM) di daerah Kabupaten Kulon Progo. https://eprints.uny.ac.id/42502/

Badan Pusat Statistika (2019). Kecamatan Sapeken dalam angka 2019. BPS Kabupaten Sumenep

Brem, A., Nylund, P. A., \& Hitchen, E. L. (2017). Open innovation and intellectual property rights: How do SMEs benefit from patents, industrial designs, trademarks and copyrights? Management Decision, 55(6), 1285-1306. https://doi.org/10.1108/MD-04-2016-0223

Ismail, I. (2011). Koperasi dan usaha mikro kecil menengah. Lembaga Penerbitan Fakultas Pertanian Universitas Brawijaya.

Mudjiarto, M. (2014). Pengaruh pembinaan manajemen usaha terhadap kinerja usaha mikro binaan PKBL PT Jasa Marga. Jurnal Ekonomi, 5(2), 80-87. https://doi.org/10.47007/jeko.v5i2.1139

Herliansyah, Y., Nugroho, L., Ardilla, D., \& Putra, Y. M. (2020). The determinants of micro, small and medium enterpreneur (MSME) become customer of Islamic Banks (Religion, religiousity and location of Islamic Banks). In The 1st Annual Conference Economics, Business, and Social Sciences (Vol. 2). https://eudl.eu/doi/10.4108/eai.263-2019.2290775

Sugiyono, S. (2018). Metodologi penelitian: Kuantitatif, kualitatif, dan research dan development (R\&D). Penerbit Alfabeta Bandung.

Surugiu, M. \& Surugiu, C. (2015). International trade, globalization and economic interdependence between european countries: implications for businesses and marketing framework. Procedia Economics and Finance, 32, 131- 138. https://doi.org/10.1016/S2212-5671(15)01374-X

Tang, S., Wang, Z., Yang, G., \& Tang, W. (2020). What are the implications of globalization on sustainability? A comprehensive study. Sustainability, 12(8), 3411. https://doi.org/10.3390/su12083411

Yanto, O., Susanto, S., Nugroho, A., Santoso, B., \& Gueci, R. S. (2020). Sosialisasi kekayaan intelektual guna menumbuhkembangkan usaha dalam rangka menghadapi persaingan global pada revolusi 4.0. Abdi Laksana: Jurnal Pengabdian Kepada Masyarakat, 1(2), 240-245. http://dx.doi.org/10.32493/al-jpkm.v1i2.4976 